\title{
Prognostic Significance in Breast Cancer of a Gene Signature Capturing Stromal PDGF Signaling
}

\author{
Oliver Frings, ${ }^{* \dagger}$ Martin Augsten, ${ }^{\ddagger}$ Nicholas P. Tobin,,${ }^{\ddagger}$ Joseph Carlson, ${ }^{\ddagger}$ Janna Paulsson, ${ }^{\ddagger}$ Cristina Pena, ${ }^{\ddagger}$ Eleonor Olsson, \\ Srinivas Veerla, ${ }^{\S}$ Jonas Bergh, ${ }^{\ddagger}$ Arne Östman, ${ }^{\ddagger}$ and Erik L.L. Sonnhammer ${ }^{* \dagger \|}$
}

\begin{abstract}
From the Stockholm Bioinformatics Centre, * Science for Life Laboratory, Solna, Sweden; the Department of Biochemistry and Biophysics, ${ }^{\dagger}$ Stockholm University, Stockholm, Sweden; the Department of Oncology and Pathology, ${ }^{\ddagger}$ Karolinska Institutet, Stockholm, Sweden; the Department of Oncology, ${ }^{\S}$ Clinical Sciences, Lund University, Lund, Sweden; University of Manchester, Paterson Institute for Cancer Research, "Manchester, United Kingdom; and the Swedish escience Research Center," Stockholm, Sweden
\end{abstract}

Accepted for publication February 7, 2013.

Address correspondence to Arne Östman, Ph.D., Department of Oncology and Pathology, Karolinska Institute, Stockholm 17176, Sweden. E-mail: arne.ostman@ki.se.

\begin{abstract}
In this study, we describe a novel gene expression signature of platelet-derived growth factor (PDGF)activated fibroblasts, which is able to identify breast cancers with a PDGF-stimulated fibroblast stroma and displays an independent and strong prognostic significance. Global gene expression was compared between PDGF-stimulated human fibroblasts and cultured resting fibroblasts. The most differentially expressed genes were reduced to a gene expression signature of 113 genes. The biological significance and prognostic capacity of this signature were investigated using four independent clinical breast cancer data sets. Concomitant high expression of PDGF $\beta$ receptor and its cognate ligands is associated with a high PDGF signature score. This supports the notion that the signature detects tumors with PDGF-activated stroma. Subsequent analyses indicated significant associations between high PDGF signature score and clinical characteristics, including human epidermal growth factor receptor 2 positivity, estrogen receptor negativity, high tumor grade, and large tumor size. A high PDGF signature score is associated with shorter survival in univariate analysis. Furthermore, the high PDGF signature score acts as a significant marker of poor prognosis in multivariate survival analyses, including classic prognostic markers, Ki-67 status, a proliferation gene signature, or other recently described stroma-derived gene expression signatures. (Am J Pathol 2013, 182: 2037-2047; http://dx.doi.org/10.1016/j.ajpath.2013.02.018)
\end{abstract}

Prognostic (tumor size, lymph node status, progesterone receptor, and histopathological grade) and therapy-predictive [estrogen receptor (ER) and human epidermal growth factor receptor 2 (HER-2)/neu] factors are routinely used for the classification and guidance of subsequent treatment decisions in breast cancer. ${ }^{1}$ To make stepwise improvements toward the goal of personalized medicine, additional predictive and prognostic factors providing further insights, compared with the present arsenal of factors, are needed to tailor therapies and to avoid undertreatment and overtreatment of patients. ${ }^{2}$

Presently, clinically used breast cancer markers are dominated by markers reflecting the biological characteristics of the tumor epithelium (eg, the proliferation index and expression of ER, progesterone receptor, and HER2). In addition to standard immunohistochemistry (IHC)-derived markers, several gene expression-based prognostic signatures have recently been presented. ${ }^{3-9}$ Most of these signatures have been designed to reflect various aspects of epithelial tumor biological characteristics (eg, epithelial-to-mesenchymal transition, ${ }^{4}$ tumor-initiating cell, ${ }^{3,5}$ cancer stem cells, ${ }^{6}$ p53 mutations, ${ }^{8}$ or iron metabolism ${ }^{7}$ ).

Recent tumor biological studies in experimental models show that tumor behavior is largely determined by properties of the tumor microenvironment. ${ }^{10}$ Critical tumor characteristics, including the ability to form metastases and to maintain a cancer stem cell population, have been shown to be controlled by the tumor microenvironment. ${ }^{11,12}$ Furthermore,

Supported by a grant from the Swedish Research Council (O.F.), the Swedish Research Council (J.B. and A.Ö.), The Swedish Cancer Society (J.B. and A.Ö.), the Breast Cancer Theme Center network financed by Karolinska Institutet (J.B.), Karolinska Institutet Foundations (J.B.), Cancer Society in Stockholm (J.B.), The King Gustaf V. Jubilee Fund (J.B.), and Stockholm County Council (J.B.).

A.Ö. and E.L.L.S. contributed equally to this work as senior authors. 
drug uptake and drug sensitivity are strongly influenced by the tumor stroma. ${ }^{13-21}$ Hence, markers accurately describing stromal biological characteristics should be able to add prognostic information that may have implications on prognostication and therapy predictions.

Most previous studies have used IHC to investigate the prognostic significance of stromal characteristics in breast cancer. $^{22-25}$ A series of publications have demonstrated an association between poor survival and loss of caveolin expression in the tumor stroma of breast cancer. ${ }^{22-24}$ In addition, some studies also indicate that loss of caveolin is also associated with worse response to endocrine treatment. ${ }^{24}$ Furthermore, high stromal platelet-derived growth factor (PDGF) receptor expression has been shown to be associated with a worse prognosis, in particular for premenopausal women. ${ }^{25}$ The importance of stromal biological characteristics for breast cancer prognosis was also recently emphasized in a multiparametric morphological feature-based analysis of large sets of breast cancer. ${ }^{26}$

More recently, several studies have used gene expression data to investigate if stromal signatures can be used for breast cancer classification and as prognostic markers. One prominent study in this category relied on a gene expression signature defining a stromal subtype linked to worse prognosis ${ }^{27}$ and the basal type of breast cancer. ${ }^{28}$ This signature was originally generated after analyses of gene expression data from microdissected fibroblast-enriched breast cancer stroma. Another stroma-related signature, with prognostic capacity, is the core serum response (CSR) signature. ${ }^{29}$ This signature was derived from analyses of serum-stimulated cultured fibroblasts, and has subsequently been shown to be possible to use as a prognostic classifier in breast cancer and other tumor types. A third example of a prognostic stroma signature is the recently described B-cell/plasma cell gene signature. $^{30}$

In this study, we have generated a gene expression signature defining fibroblasts stimulated with PDGF. This signature was subsequently applied as a classifier, using multiple publicly available breast cancer gene expression data sets. The signature showed a striking ability to divide breast cancers into high- and low-risk groups. This prognostic capacity was also detected in multivariate analyses when combined with either classic clinical characteristics or other stromal gene expression signatures.

\section{Materials and Methods}

\section{Patient Data and Published Gene Expression Data Sets}

In this study, four public breast cancer data sets were used. The Uppsala data set contains expression profiles for 251 patients who were all treated in Uppsala, Sweden, between 1987 and 1989. ${ }^{8}$ The Stockholm data set contains expression profiles for 159 patients who were treated at Karolinska University Hospital (Stockholm, Sweden) between 1994 and $1996 .{ }^{31}$ The Netherlands Cancer Institute (NKI) data set contains expression data for 295 patients with breast cancer from the NKI (Netherlands). ${ }^{32}$ All patients were diagnosed between 1984 and 1995. Additional clinical data were made available by Fan et al. ${ }^{33}$ The Rotterdam data set comprises expression data for 286 patients from the Erasmus Medical Center (Rotterdam, The Netherlands). ${ }^{34}$

Classification according to the intrinsic subtype model (basal, Her2, luminal A, luminal B, or normal-like) was obtained from the original publications in case of the Stockholm, NKI, and Rotterdam data. For the Uppsala data set, the $\mathrm{R}$ genefu package was used to predict subtypes according to the intrinsic gene list described by Sorlie et al. ${ }^{35}$

The averaged expression of the PDGF $\beta$ receptor (PDGF $\beta R$ ) ligands PDGF-B and PDGF-D was calculated using the arithmetic mean of PDGF-B and PDGF-D expression levels.

\section{PDGF Signature}

A total of $1.2 \times 10^{6}$ BJhTERT fibroblasts were cultured in $10-\mathrm{cm}$ dishes in Dulbecco's modified Eagle's medium (Gibco Life Technologies, Gergy-Pontoise, France) supplemented with $1 \%$ heat-inactivated fetal calf serum, $2 \mathrm{mmol} / \mathrm{L}$ L-glutamine, $100 \mathrm{U} / \mathrm{mL}$ penicillin, and $100 \mathrm{ng} / \mathrm{mL}$ streptomycin and kept at $37^{\circ} \mathrm{C}$ in a $5 \% \mathrm{CO}_{2}$ humidified atmosphere for 24 hours. Cultures were incubated with or without $20 \mathrm{ng} / \mathrm{mL}$ PDGF-B (Peprotech, Rocky Hill, NJ) for another 24 hours before harvest.

Total RNA from three replicates of each PDGF-Bstimulated and non-stimulated control cell was extracted using the TRIzol (Life Technologies Europe BV, Stockholm, Sweden) and the RNeasy Mini Kit (Qiagen Inc., Hilden, Germany), followed by purification using the RNeasy micro kit (Qiagen Inc.) and hybridization to HumanHT-12, version 3.0, Expression BeadChips (Illumina Inc., San Diego, CA) at the Swegene Center for Integrative Biology at Lund University (Lund, Sweden).

Data management and normalization were performed using BeadStudio, version 3.1.3.0, Software (Illumina Inc.). Raw intensity values represent mean bead pool intensity values for each probe. Data were normalized using a quantile normalization algorithm, as implemented in BeadStudio, version 3.1.3.0, Software. Probes were mapped to RefSeq Release 22 (National Center for Biotechnology Information Build 36.2) and UniGene Build 199. Only probes with an annotated gene symbol were used in further analyses.

Probe identifiers were mapped to Entrez gene identifiers, according to manufacturer's annotation files. Genes differentially expressed between fibroblasts stimulated with PDGF-B and control cells were identified with the R MWT package version 0.2.6. ${ }^{36}$ The MWT package implements a moderated Welch test that accounts for unequal group variances, making it suitable for experiments with a low sample number. In case of multiple probe sets corresponding to the same gene ID, the one with the most significant $P$ value was kept. These $P$ values were adjusted for multiple testing 
using the false-discovery rate (FDR) with the procedure outlined by Benjamini and Hochberg. ${ }^{37}$

All genes with an FDR $<0.05$ were ranked according to their FDR, and the list of the 200 most up-regulated and 200 most down-regulated genes was extracted. An initial PDGF signature score was derived by calculating Pearson's correlation coefficient between the $\log 2$ expression values of the signature genes in the PDGF-B-stimulated fibroblasts and the $\log 2$ expression values of corresponding genes in the Uppsala data set, in which expression values were centered using the mean expression of each gene. In the PDGFB-stimulated data set, expression values for the three replicates were averaged, yielding 251 assessments of similarity between clinical breast cancer profiles and the representative cell culture changes in PDGF-B-stimulated fibroblasts.

Among the initial 400 genes, a reduced gene set was identified. This was done to reduce the number of genes and, at the same time, identify the genes most relevant to clinical sample profiles. This analysis was performed without considering the prognostic capacity of the individual genes and using expression data from the Uppsala data set. In detail, for each of the 400 original genes, the correlation between the expression of that gene in the 251 samples of the Uppsala data and the PDGF signature score of the respective samples was calculated. Only genes with a correlation significant at the $P<0.001$ level were included in the reduced signature. This procedure resulted in a signature of 113 genes, including 55 up-regulated and 58 down-regulated genes.

Signature scores for all cases of the four clinical data sets were subsequently calculated using the reduced 113-gene signature.

\section{G0 Analysis}

The significance of the enrichment of Gene Ontology (GO) terms for genes in the PDGF signature was assessed using a hypergeometric test. The FDRs were estimated using the procedure of Benjamini and Hochberg. ${ }^{37}$ Terms significantly enriched with an FDR $<5 \%$ were identified for up-regulated and down-regulated genes together. The list of enriched GO terms was further reduced using GO-Module. ${ }^{38}$ GO-Module summarizes a list of hierarchically encapsulated GO terms to one representative term (the most significant one).

\section{Analyses of Ki-67 Status}

Staining was performed on serial sections ( $4 \mu \mathrm{m}$ thick) from paraffin-embedded tumors. Sections were deparaffinized and treated with target retrieval solution (EnvisionTM Flex; Dako, Glostrup, Denmark) for 20 minutes at $97^{\circ} \mathrm{C}$. Staining was performed in the Dako Autostainer Plus automated slide processing system (Dako) with a 1:100 dilution of anti-Ki-67 E MIB-1 antibody. Staining was evaluated by an experienced pathologist (J.C.) without prior knowledge of patient outcome or tumor characteristics. Cells with nuclear expression of Ki-67 were considered positive for disease. Information on Ki-67 status could only be obtained for a subset of patients; such data were obtained for 113 patients from the Stockholm cohort and for 233 patients from the Uppsala cohort.

\section{RT-qPCR Analyses}

BJhTert-immortalized fibroblasts were plated in 6-cm plates (Dulbecco's modified Eagle's medium supplemented with $10 \%$ fetal calf serum, glutamine, and penicillin streptomycin) and starved in $1 \%$ fetal calf serum for 24 hours. PDGF-BB $(20 \mathrm{ng} / \mathrm{mL}$ ) was then added to the media for 24 hours before preparation of RNA. RNA was prepared from two controls and two PDGF-BB-stimulated plates using the GenElute Mammalian Total RNA Miniprep kit, according to the manufacturer's instructions, including DNase I digestion (RTN70; Sigma Aldrich, St. Louis, MO). RNA concentration was measured using a NanoDrop ND-100 spectrophotometer (NanoDrop Technologies, Wilmington, DE). cDNA synthesis and quantitative RT-PCR (RT-qPCR; Applied Biosystems, Foster City, CA) was done, as described by Augsten et al. ${ }^{39}$ In detail, cDNA synthesis was done with the SuperScript III (Life Technologies Europe BV), and $10 \mathrm{ng}$ was used for the RTqPCR. Quantitative real-time PCR was performed with SYBR Green universal PCR master mix (Applied Biosystems, Foster City, CA) on the 7500 Real-Time PCR system (Applied Biosystems). Primers (PTGS2, MMP1, HMGA1, SYT7, TMEM200A, PHLDA1, FOXQ1, HAS2, SLC20A1, ERRFI1, CSRP2, GSTM1, CORIN, PPIC, SGIP1, LYPD6, CDH2, PGRMC2, PLA2G16, PDGFRL, TRPV2, TCP1, RNF24, CTSL1, CTGF, TCF19, CCL2, OLR1, SULF1, and ERBB3) were purchased from Qiagen Inc. (QuantiTect Primer Assay) and used according to the manufacturer's instructions. Expression levels were normalized to glyceraldehyde-3phosphate dehydrogenase expression and analyzed using $\Delta C_{T}$.

\section{Comparison with Other Stroma-Derived Predictors}

We compared our results with three external stroma-derived predictors: the CSR signature, ${ }^{29}$ the classifier by Finak et al, ${ }^{27}$ and the B-cell signature. ${ }^{30}$ Expression patterns for the CSR genes were downloaded from the Stanford Microarray database. In accordance with Chang et $\mathrm{al},{ }^{40}$ the Pearson correlation of the serum-activated fibroblast centroids and breast cancer samples was calculated. To reproduce the results of Finak's stromaderived prognostic predictor, the 26-gene signature defined in the original publication was used to train a bayesian classifier, as described in Wennmalm et al. ${ }^{28}$ Samples were grouped into poor, mixed, and good outcomes. The set of 39 probe identifiers in the B-cell gene signature by Bianchini et al ${ }^{30}$ were mapped to a set of 22 unique Entrez gene identifiers. The B-cell gene signature score was then derived by taking the arithmetic mean of the $\log _{2}$ expression values of all gene identifiers.

\section{Survival Analysis}

All analyses, including Cox proportional hazards regression and Kaplan-Meier survival curves, were conducted in $\mathrm{R}$ 
(http://www.r-project.org). For the survival analysis, the meta-proliferating cell nuclear antigen (PCNA) score, the B-cell score, the PDGF signature score, the CSR signature score, age of patients, and the tumor size were modeled as continuous variables. For the PDGF and the CSR signatures, the hazard ratio reported is per one $(10 \%)$ increment of the correlation value. The tumor grade $\left(\mathrm{G}_{1}, \mathrm{G}_{2}\right.$, and $\left.\mathrm{G}_{3}\right)$, the lymph node status $\left(\mathrm{LN}^{-}\right.$and $\left.\mathrm{LN}^{+}\right)$, the ER status $\left(\mathrm{ER}^{-}\right.$and $\mathrm{ER}^{+}$), and the Finak predictor (poor, good, and mixed) were modeled as categorical variables. The Ki-67 status for the Stockholm and Uppsala data was modeled as a binary variable using a cutoff of $14 \%$, which has previously been identified by Cheang et $\mathrm{al}^{41}$ as providing strong prognostic separation of $\mathrm{ER}^{+}$patients with breast cancer.

\section{Random Gene Signatures}

As a negative control, 1000 random gene signatures of 113 genes were generated 10 times, and their prognostic capacity was compared against that of the PDGF signature. Signatures were derived by randomly sampling 113 genes from our data set of PDGF-B - stimulated fibroblasts. Signature scores were calculated in a similar manner as for the original PDGF signature by calculating Pearson's correlation coefficient between the $\log 2$ expression values of the signature genes in the PDGF-B-stimulated fibroblasts and the $\log 2$ expression values of the corresponding genes in the respective breast cancer data sets. Random signatures were further filtered for those that showed a prognostic capacity at $P<0.01$ on all four breast cancer cohorts. Finally, the number of signatures that showed a prognostic capacity higher than that of the original PDGF signature was determined.

To assess the prognostic capacity of the random signatures, we used data on disease-specific survival (DSS) for the Uppsala data and data on recurrence-free survival (RFS) for the other data sets.

\section{Results}

\section{A PDGF Signature Identifies Breast Cancers Co-Expressing PDGF $\beta R$ and Its Ligands}

PDGF receptor signaling in breast cancer occurs predominantly in fibroblasts and pericytes. ${ }^{25}$ To generate a gene signature that could potentially capture this process in tumor gene expression data sets, we performed differential expression analysis of cultured resting versus PDGF-stimulated human fibroblasts. From these data, a list of 400 PDGFregulated genes (200 up-regulated and 200 down-regulated genes) was extracted.

The expression of these genes was initially analyzed in the Uppsala data set and used to generate an initial PDGF signature score for each individual tumor. Based on this analysis, which did not include any associations between signature score and clinical outcome characteristics, a shorter list of 113 genes (55 up-regulated and 58 down-regulated genes) was generated that contains only the genes acting as major drivers of the signature (see Materials and Methods for details). PDGF-dependent upregulation and down-regulation of 10 up-regulated and 10 down-regulated genes were further validated in an RT-qPCR analysis that yielded results that in 19 of 20 cases were concordant with the microarray analyses (Supplemental Figure S1). Throughout the rest of the study, the 113-gene signature will be referred to as the PDGF signature. The list of 113 PDGF signature genes is available in Supplemental Table S1.

The GO analysis revealed that the signature mostly represents functions or processes of immediate relevance to the tumor microenvironment and includes regulators of angiogenesis and the extracellular matrix (Supplemental Table S2).

The PDGF signature was designed to identify tumors with ligand-activated stromal PDGF receptors. A hallmark of such tumors should be high expression of the PDGF $\beta$ R and its cognate ligands (PDGF-B and PDGF-D). We proceeded to investigate the relation between the PDGF signature score and the expression of PDGF $\beta R$ and PDGFB/D using four tumor data sets.

As shown in Figure 1, a strong association exists between PDGF receptor expression and expression of PDGF-B and PDGF-D (Spearman correlation $=0.43, P=9.71 \times$ $10^{-44}$ ). Furthermore, samples with a high PDGF signature score were significantly enriched in the upper right quadrant of the diagram, representing tumors characterized by high levels of PDGF $\beta$ R and cognate ligands $(P<0.01$ for the top 10\%) (Supplemental Table S3). Similarly, there was also a significant enrichment of tumors with a low score in the lower left quadrant, representing tumors with low ligand and

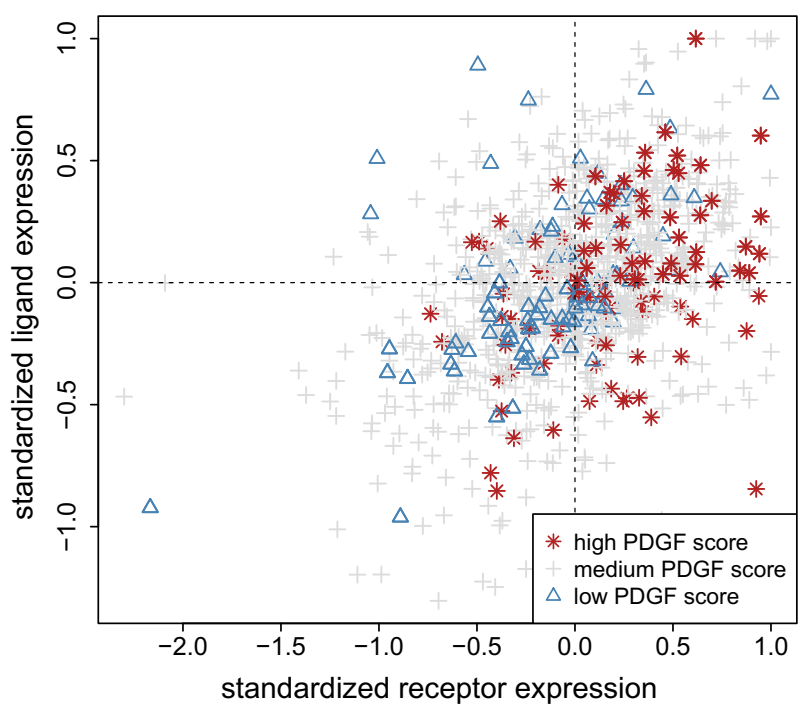

Figure 1 High expression of PDGF receptor and ligands is associated with high PDGF signature score. The figure shows the expression of PDGF $\beta$ receptor on the $x$ axis and the averaged expression of PDGF-B and PDGF-D on the $y$ axis. The analysis was conducted on all four tumor data sets combined. Samples are marked according to their PDGF signature score. The top $10 \%$ of scores are red stars, the bottom $10 \%$ of scores are blue triangles, and the rest are gray plus signs. Samples with a high PDGF signature score were significantly enriched in the upper right quadrant, representing tumors with high expression levels of PDGF receptor and its cognate ligands. 
receptor expression $(P<0.001$ for the bottom 10\%) (Supplemental Table S3). Similar results were obtained when analyses were performed on the $25 \%$ of tumors with the lowest score and the $25 \%$ of tumors with the highest score (Supplemental Table S3).

Together, these results support the notion that the PDGF signature detects the activation state of PDGF $\beta R$ in breast cancer stroma.

\section{The PDGF Signature Is Associated with Many Clinical Subtypes of Breast Cancer}

To investigate the relationship between the PDGF signature score and clinical and pathological characteristics of breast cancer, patients were split into two groups based on the median signature score. Strong associations between PDGF signature score and many clinical characteristics were observed in analyses of four large breast cancer data sets (Table 1). A high PDGF signature score was significantly associated $(P<0.05)$ with high tumor grade, young age, large tumors, and ER negativity.

A high PDGF signature score was also strongly associated with breast cancer molecular subtypes, specifically the HER2 ${ }^{+}$, basal-like, and luminal B groups. Together, these results demonstrate a strong association between PDGF signature score and clinicopathological and molecular characteristics found in poor outcome subtypes of breast cancers.

\section{High PDGF Signature Score Is an Independent Marker for Shorter Survival in Breast Cancer}

To assess the capacity of the PDGF signature to predict survival, a univariate analysis was initially conducted.
The analysis demonstrated an increased risk (hazard ratio, $>1 ; P<0.05)$ for patients with a high PDGF signature score in all four data sets (Table 2). The increased risk was observed in analyses of DSS, overall survival, and RFS.

Figure 2 shows Kaplan-Meier survival curves for the combined tumor data set (survival curves for the individual data sets are available in Supplemental Figure S2). Patients were divided into two equally sized groups based on the signature score. A high PDGF signature score was associated with shorter DSS (Uppsala and Stockholm) and RFS (Stockholm, Rotterdam, and NKI).

Associations between patient survival and PDGF signature score were also analyzed in different breast cancer subgroups. Supplemental Table S4 summarizes the results of these univariate analyses based on RFS. A significant association between high PDGF signature score and poor survival was observed in the groups of $\mathrm{LN}^{+}, \mathrm{ER}^{+}$, luminal $\mathrm{A}$, and grade 1 and 2 breast cancers.

To assess whether the prognostic ability of the PDGF signature is independent of other established risk factors, including markers related to proliferation, a set of multivariate analyses was conducted. Analyses of the Uppsala data set, which includes the status of the known proliferation marker protein $\mathrm{Ki}-67$, demonstrated that the PDGF signature is an independent marker for survival in this data set (Table 3). This was also true for the NKI data set, in a multivariate analysis including the meta-PCNA proliferation signature $^{42}$ (Table 3). For the Stockholm and Rotterdam data, clinical parameters were missing, and multivariate analyses were performed in which the PDGF signature was analyzed together with the meta-PCNA signature in the Rotterdam data set and with Ki-67 in the Stockholm data. The PDGF signature showed strong prognostic capacity

Table 1 Associations between PDGF Signature Score and Clinicopathological Characteristics in Four Different Breast Cancer Cohorts

\begin{tabular}{|c|c|c|c|c|c|c|c|c|c|c|c|c|c|}
\hline \multirow{2}{*}{ Variable } & & \multicolumn{3}{|l|}{ NKI } & \multicolumn{3}{|c|}{ Uppsala } & \multicolumn{3}{|c|}{ Stockholm } & \multicolumn{3}{|c|}{ Rotterdam } \\
\hline & & Low & High & $P$ value & Low & High & $P$ value & Low & High & $P$ value & Low & High & $P$ value \\
\hline \multirow{3}{*}{$\begin{array}{l}\text { Count } \\
\text { Tumor grade }\end{array}$} & & 148 & 147 & & 118 & 118 & & 80 & 79 & & 143 & 143 & \\
\hline & $\mathrm{G}_{2}$ & 59 & 42 & $6.39 \times 10^{-7}$ & 63 & 58 & $3.32 \times 10^{-9}$ & 32 & 26 & $6.62 \times 10^{-3}$ & & & \\
\hline & $\mathrm{G}_{3}$ & 38 & 81 & & 8 & 43 & & 21 & 40 & & & & \\
\hline \multicolumn{2}{|c|}{ Average age (years) } & 44.1 & 43.9 & $9.63 \times 10^{-1}$ & 65.7 & 59.4 & $4.13 \times 10^{-4}$ & & & & & & \\
\hline \multicolumn{2}{|l|}{$\mathrm{ER}^{+}$} & 129 & 96 & $1.01 \times 10^{-5}$ & 107 & 94 & $2.69 \times 10^{-2}$ & & & & 115 & 94 & $7.44 \times 10^{-3}$ \\
\hline \multirow[t]{4}{*}{ Subtype } & $\mathrm{HER}^{+}{ }^{+}$ & 14 & 21 & & 1 & 17 & & 6 & 9 & & 13 & 24 & \\
\hline & Basal-like & 7 & 46 & & 2 & 18 & & 8 & 17 & & 15 & 44 & \\
\hline & Normal-like & 12 & 17 & $1.01 \times 10^{-12}$ & 1 & 1 & $4.81 \times 10^{-9}$ & 24 & 13 & $1.72 \times 10^{-2}$ & 20 & 8 & $3.44 \times 10^{-7}$ \\
\hline & Luminal A & 90 & 33 & & 112 & 76 & & 25 & 14 & & 73 & 41 & \\
\hline
\end{tabular}

All samples were grouped into two equally sized bins based on the median signature score. The distribution of the number of samples with a signature score higher than the median (high) and lower than the median (low) in each data set and category is shown. The significance of enrichment or depletion between the groups was assessed using the Fisher's exact test. For tumor grade and subtype, the $P$ value was calculated for all subtypes combined and indicates the joint probability that they were all sampled from the same distribution. For age and size, the significance of the distributions between the low and high signature groups was assessed using a Wilcoxon rank sum test. Note that some parameters were missing for the Stockholm and Rotterdam data and that some of the cells are therefore left empty. 
Table 2 Univariate Analyses of the Ability of the PDGF Signature and Clinical Characteristics to Predict DSS, OS, and RFS in Four Different Breast Cancer Data Sets

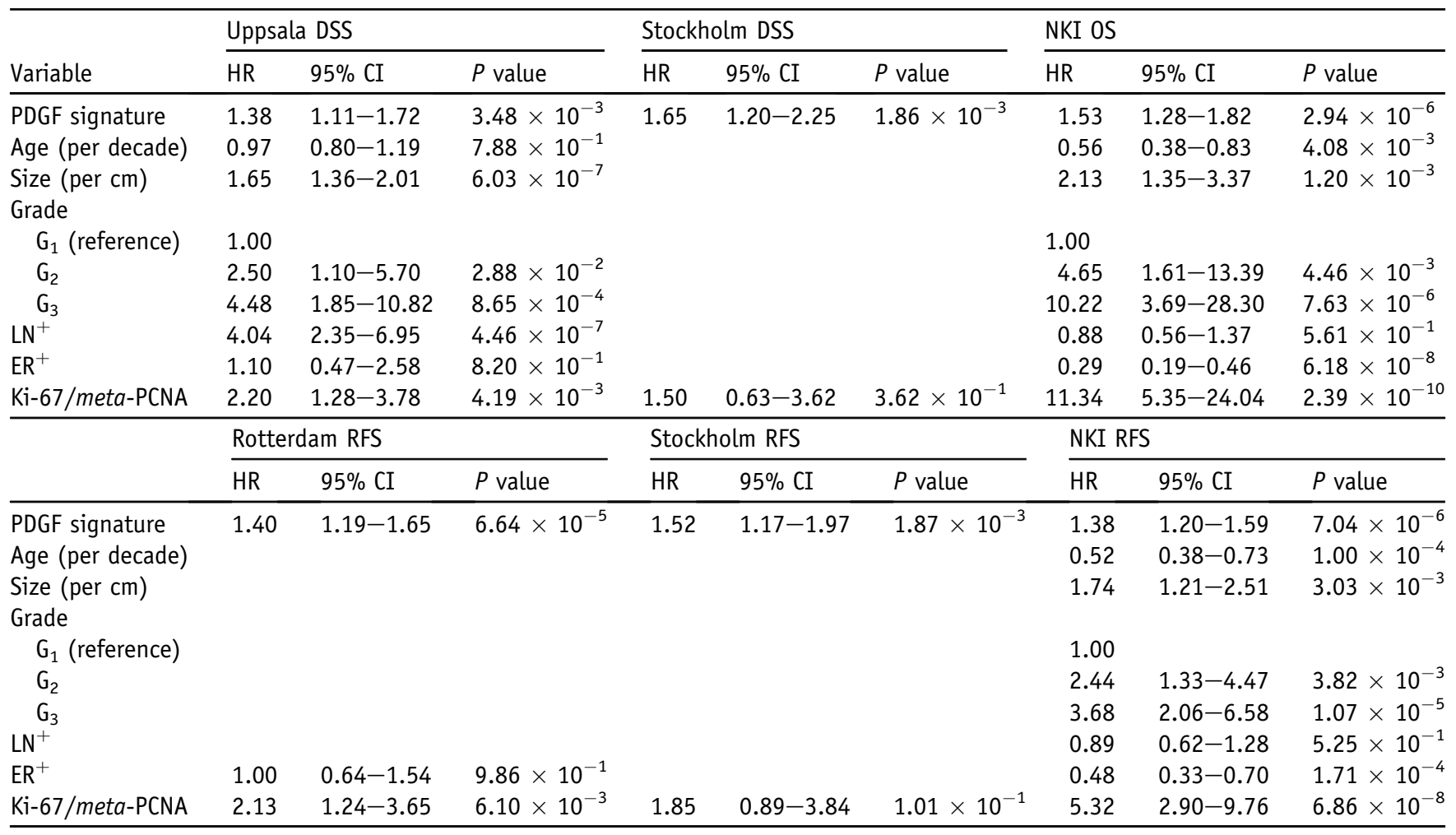

DSS data were only available for the Stockholm and Uppsala groups, overall survival data were only available for the NKI group, and RFS data were only available for the Rotterdam, NKI, and Stockholm groups. Only the Uppsala and NKI groups contained full data on the listed clinical characteristics. Ki-67 status was used as a marker for proliferation for the Uppsala and Stockholm groups, and the meta-PCNA signature was used as a proliferation marker for the NKI and Rotterdam groups. Note that some parameters were missing for the Stockholm and Rotterdam data and that some of the cells are therefore left empty.

$H R$, hazard ratio; $O R$, overall survival.

together with the meta-PCNA signature in the Rotterdam data set (Table 3). In the Stockholm data set, a significant prognostic role of the PDGF signature was observed in the multivariate analysis with $\mathrm{Ki}-67$ when RFS was used as the end point, whereas a trend $(P=0.09)$ was observed with DSS as the end point (Table 3).

Finally, the PDGF signature was analyzed together with the meta-PCNA signature in data sets including patients from multiple data sets. Two data sets were compiled, one containing DSS data from the Stockholm and Uppsala data sets and one containing information on RFS from the Stockholm, NKI, and Rotterdam cohorts. As shown in Table 4, the PDGF signature remained a strong prognostic indicator of survival $(P<0.05)$ in the analyses of the combined breast cancer cohorts.

Together, these analyses demonstrate that a high PDGF signature score is a marker for poor prognosis, which is independent of traditional markers such as grade, tumor size, lymph node status, and ER status. The analyses also demonstrate that the PDGF signature contains prognostic information not captured by Ki-67 status or the proliferationrelated meta-PCNA signature. This implies that the PDGF signature detects biological properties of prognostic significance that are distinct from cancer cell proliferation.
The PDGF Signature Is an Independent Marker for Survival When Analyzed Together with Other Stromal Signatures

The PDGF signature was also compared with other stromaderived predictors: the CSR signature, ${ }^{29}$ the stroma classifier of Finak et al, ${ }^{27}$ and the B-cell signature. ${ }^{30}$ In agreement with previous analyses, the CSR signature and the poor prognosis signature of Finak et al were generally associated with poor prognosis in univariate analyses of DSS, overall survival, and RFS (Table 5). In agreement with the results of Bianchini et $a l,{ }^{30}$ the B-cell signature was associated with good outcome on the Rotterdam data. Although this signature did not show a significant association with outcome on the complete Uppsala and Stockholm data, the prognostic power of the signature increased when limited to tumors of the luminal B subtype. Those tumors are known to have higher expression of proliferation-related genes. This coincides with Bianchini's findings that the signature works best on ERpositive highly proliferative cancers. The loss of prognostic capacity of the B-cell signature on the NKI data, when restricted to luminal B tumors, is most likely the result of the few gene identifiers on the chip used in this study that could be mapped to the genes in the signature. 

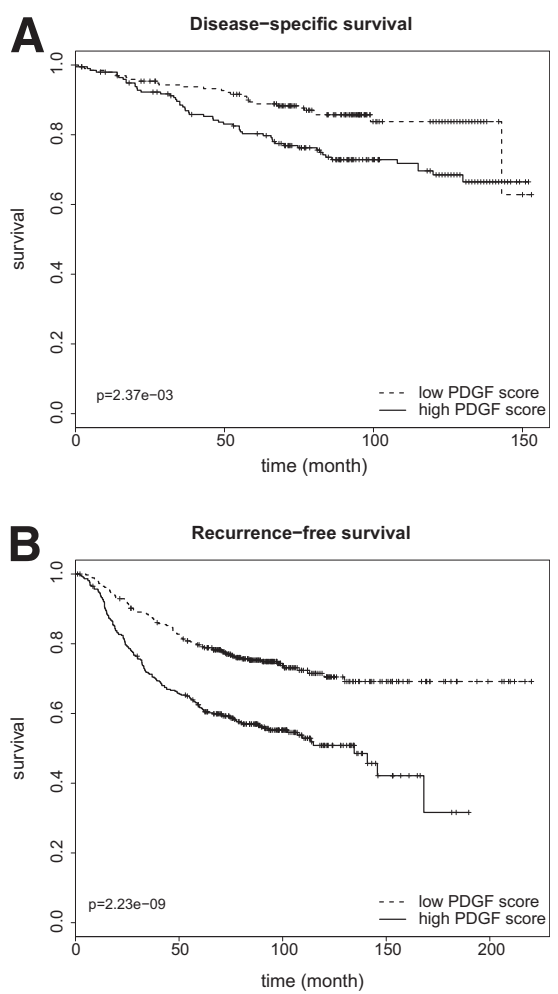

Figure 2 High PDGF signature score is associated with shorter survival. Kaplan-Meier analyses of DSS (A) and RFS (B) on combined breast cancer cohorts. The DSS data were available for the Stockholm and Uppsala data, and RFS data were available for the Rotterdam, NKI, and Stockholm data. Samples were grouped into two equally sized bins based on their PDGF signature score. Patients with a high PDGF signature score have shorter survival than patients with a low signature score. The hazard ratios for DSS and RFS were $1.8\left(P=7.94 \times 10^{-3}\right)$ and $2.1\left(P=1.70 \times 10^{-8}\right)$, respectively.

To investigate if these signatures detect independent prognosis-related biological characteristics, a multivariate analysis was performed (Table 5). The PDGF signature remained a significant prognostic factor in all analyses. The B-cell signature did not show any significant prognostic capacity, together with the other predictors. The Finak poor prognosis stroma signature was prognostically significant in some, but not all, data sets, suggesting that the prognostic biological characteristics of this signature are also detected by the other signatures. The CSR signature performed better but did not show any significant prognostic capacity for DSS in the Stockholm data or RFS in the Rotterdam data.

Together, these analyses indicate that the PDGF signature captures biological properties, associated with worse prognosis, that are not captured by the other stroma-derived predictors.

\section{Discussion}

In the present study, we describe a novel gene expression signature that detects stromal PDGF receptor signaling and also displays prognostic significance on multiple large breast cancer data sets. The signature also retains prognostic significance when analyzed in multivariate analyses, together with established breast cancer risk factors and other recent stroma-related signatures. More important, the signature remained significant in multiple analyses that also included markers of cancer cell proliferation, such as Ki-67 status or the meta-PCNA signature. As such, our signature differs from other recent signatures, in which the prognostic significance has been argued to be related to the ability to detect cell proliferation and ER-regulated pathways. ${ }^{9,42,43}$

One key finding, from a mechanistic and tumor biological feature perspective, of the present study is that stromal PDGF receptor activation is associated with bad prognosis in breast cancer. This provides independent support for previous findings made in experimental models and through analyses of human tumor material. ${ }^{44,45}$ A tumor-promoting effect of PDGF stimulation of the tumor stroma was originally suggested in studies that demonstrated that transfection with PDGF-B chain cDNA increased the ability of melanoma cells to induce tumors through enhanced fibroblast recruitment. ${ }^{46}$ Other similar studies in skin cancer models confirmed these observations. ${ }^{47}$ Experimental studies have also demonstrated that PDGF receptor signaling in pericytes can promote tumor growth. $^{48,49}$ Most recently, analyses of colorectal cancer models have shown that PDGF-stimulated fibroblasts can promote metastasis. $^{50}$

Clinical relevance of stromal PDGF receptor signaling is supported by recent studies demonstrating, through analyses of large series of human tumors, that high stromal PDGF receptor expression is associated with worse prognosis in breast and prostate cancer. ${ }^{25,51}$ In the previous IHC-based analysis of prognostic significance of stromal PDGF $\beta$ receptor expression, the results were not significant in multivariate analyses, including standard prognostic factors. A potential explanation for the improved prognostic capacity of the PDGF signature, compared with PDGF $\beta$ R IHC, is that the PDGF signature detects PDGF receptor signaling, whereas the IHC analysis only considers receptor expression. This could eventually be further analyzed in future studies by comparing results obtained with the PDGF signature with results from the novel proximity-ligation-based assay of PDGF receptor activation. ${ }^{52-54}$

The present study strongly suggests that the prognostic capacity of the novel signature is linked to its ability to monitor stromal PDGFR signaling. However, it cannot be excluded that the prognostic ability of the PDGF signature also involves an ability to detect other processes than stromal PDGF $\beta$ receptor signaling. Further analyses will be possible to perform when novel improved tools for specific and robust monitoring of stromal PDGF $\beta$ receptor signaling have been developed.

The present findings add to a growing list of studies in which gene expression profiles monitoring the biological characteristics of the tumor stroma display prognostic significance. ${ }^{27,29,30,55}$ Various approaches have been used to generate these signatures, including comparison of stroma of good and poor prognosis tumors, analyses of resting and 
Table 3 Multivariate Analyses of the Ability of the PDGF Signature, Clinical Characteristics, and Proliferation Markers to Predict DSS, 0S, and RFS in Four Different Breast Cancer Data Sets

\begin{tabular}{|c|c|c|c|c|c|c|c|c|c|}
\hline \multirow[b]{2}{*}{ Variable } & \multicolumn{3}{|c|}{ Uppsala DSS } & \multicolumn{3}{|c|}{ NKI OS } & \multicolumn{3}{|c|}{ NKI RFS } \\
\hline & $\mathrm{HR}$ & $95 \% \mathrm{CI}$ & $P$ value & $\mathrm{HR}$ & $95 \% \mathrm{CI}$ & $P$ value & $H R$ & $95 \% \mathrm{CI}$ & $P$ value \\
\hline PDGF signature & 1.32 & $1.02-1.70$ & $3.56 \times 10^{-2}$ & 1.23 & $1.01-1.51$ & $4.22 \times 10^{-2}$ & 1.19 & $1.02-1.40$ & $3.14 \times 10^{-2}$ \\
\hline Size (per $\mathrm{cm}$ ) & 1.36 & $1.07-1.74$ & $1.00 \times 10^{-2}$ & 1.36 & $0.84-2.20$ & $2.07 \times 10^{-1}$ & 1.31 & $0.90-1.93$ & $1.62 \times 10^{-1}$ \\
\hline \multicolumn{10}{|l|}{ Grade } \\
\hline $\mathrm{G}_{1}$ (reference) & 1.00 & & & 1.00 & & & 1.00 & & \\
\hline $\mathrm{LN}^{+}$ & 2.53 & $1.38-4.64$ & $2.78 \times 10^{-3}$ & 1.07 & $0.67-1.70$ & $7.78 \times 10^{-1}$ & 0.97 & $0.66-1.40$ & $8.53 \times 10^{-1}$ \\
\hline $\mathrm{ER}^{+}$ & 1.51 & $0.63-3.63$ & $3.52 \times 10^{-1}$ & 0.61 & $0.36-1.03$ & $6.45 \times 10^{-2}$ & 0.87 & $0.55-1.38$ & $5.56 \times 10^{-1}$ \\
\hline \multirow[t]{2}{*}{ Ki-67/meta-PCNA } & 1.33 & $0.71-2.50$ & $3.79 \times 10^{-1}$ & 3.14 & $1.22-8.08$ & $1.73 \times 10^{-2}$ & 2.72 & $1.23-6.00$ & $1.31 \times 10^{-2}$ \\
\hline & \multicolumn{3}{|c|}{ Stockholm DSS } & \multicolumn{3}{|c|}{ Stockholm RFS } & \multicolumn{3}{|c|}{ Rotterdam RFS } \\
\hline
\end{tabular}

Only the Uppsala and NKI sets contained data on all listed clinical characteristics. Ki-67 status was used as a marker for proliferation for the Uppsala and Stockholm groups, and the meta-PCNA signature was used as a proliferation marker for the NKI and Rotterdam groups.

$H R$, hazard ratio; OS, overall survival.

serum-activated fibroblasts, and analyses of genes present in tumor preparations consisting of either the composite tumor or only epithelial cells. The latter approach specifically identified a B-cell/plasma cell gene signature with prognostic significance. ${ }^{30}$ Our multivariate analyses using two of these other stroma signatures indicated that the different stroma-derived signatures, in some of the data sets, acted as independent prognostic markers. This suggests that the signatures capture different independent aspects of stromal tumor biological characteristics. These findings also suggest that additional signatures reflecting other stroma components, such as vascular characteristics, might add additional prognostic information. The approach used in our study could further be applied to determine the prognostic relevance of other fibroblast-stimulatory pathways, such as hedgehog and TGF- $\beta$ signaling.

It is increasingly recognized that different prognostic markers are of variable relevance for various types of breast

Table 4 Multivariate Analyses Including the PDGF Signature and the meta-PCNA Signature

\begin{tabular}{|c|c|c|c|}
\hline Variable & HR & $95 \% \mathrm{CI}$ & $P$ value \\
\hline \multicolumn{4}{|c|}{ Multivariate DSS Combined } \\
\hline PDGF signature & 1.15 & $1.03-1.30$ & $1.62 \times 10^{-2}$ \\
\hline meta-PCNA & 1.21 & $1.10-1.34$ & $1.90 \times 10^{-4}$ \\
\hline \multicolumn{4}{|c|}{ Multivariate RFS Combined } \\
\hline PDGF signature & 1.16 & $1.09-1.23$ & $3.45 \times 10^{-6}$ \\
\hline meta-PCNA & 1.18 & $1.11-1.25$ & $2.05 \times 10^{-7}$ \\
\hline
\end{tabular}

DSS data were collected from the Stockholm and Uppsala groups, and RFS information was collected from the Stockholm, NKI, and Rotterdam groups. $H R$, hazard ratio. cancer. Recent findings suggest that this is also the case for stroma-related signatures. For example, the B-cell/plasma cell gene signature was strongly prognostic in the ERpositive highly proliferative cases, whereas it did not show any significance in the analyses of ER-positive tumors with low proliferation. ${ }^{30}$ Similar findings were also made in the univariate analyses of the PDGF signature that demonstrated strong prognostic significance in, for example, $\mathrm{ER}^{+}$and lower-grade tumors (Supplemental Table S4).

A recent meta-analysis demonstrated similar relative benefit of chemotherapy among various breast cancer groups. ${ }^{56}$ It is nevertheless generally accepted that better predictors of sensitivity to various treatments are highly warranted. This study does not address the issue of responsepredictive significance of the PDGF receptor signature. However, such analyses are motivated by numerous recent experimental and clinical studies that, in breast cancer or other tumor types, have provided evidence that the tumor microenvironment controls response to treatment. ${ }^{18,57}$ Experimental studies have suggested multiple mechanisms, including effects of tumor stroma on either tumor cell exposure to drugs or tumor cell sensitivity to drugs. ${ }^{13,14,17,19-21}$ Stromal PDGF receptor signaling has specifically been linked to treatment response through its ability to modulate tumor drug uptake by its impact on interstitial fluid pressure. ${ }^{15,16,58,59}$ The availability of the PDGF signature should allow a set of studies, ideally performed on tumor gene expression data from randomized studies, to stringently investigate relationships between the signature score and benefit of treatment.

It has been shown that random gene signatures can be equally good or even better outcome predictors for cancer than published signatures of identical size. ${ }^{42}$ To address this 
Table 5 Univariate and Multivariate Analyses of the Prognostic Significance of the PDGF Signature and Other Stroma-Related Gene Expression Signatures

\begin{tabular}{|c|c|c|c|c|c|c|c|c|c|}
\hline \multicolumn{10}{|l|}{ Univariate } \\
\hline & \multicolumn{3}{|c|}{ Uppsala DSS } & \multicolumn{3}{|c|}{ Stockholm DSS } & \multicolumn{3}{|c|}{ NKI OS } \\
\hline & $\mathrm{HR}$ & $95 \% \mathrm{CI}$ & $P$ value & $\mathrm{HR}$ & $95 \% \mathrm{CI}$ & $P$ value & $H R$ & $95 \% \mathrm{CI}$ & $P$ value \\
\hline Good (reference) & 1.00 & & & 1.00 & & & 1.00 & & \\
\hline Poor & 1.38 & $0.49-3.88$ & $5.47 \times 10^{-1}$ & 4.42 & $1.30-14.96$ & $1.70 \times 10^{-2}$ & 4.16 & $1.85-9.33$ & $5.47 \times 10^{-4}$ \\
\hline CSR & 1.31 & $1.13-1.51$ & $2.79 \times 10^{-4}$ & 1.27 & $1.04-1.56$ & $2.11 \times 10^{-2}$ & 1.37 & $1.20-1.57$ & $5.86 \times 10^{-6}$ \\
\hline B cell & 0.83 & $0.56-1.23$ & $3.47 \times 10^{-1}$ & 1.12 & $0.66-1.92$ & $6.73 \times 10^{-1}$ & 1.47 & $1.00-2.15$ & $4.83 \times 10^{-2}$ \\
\hline \multirow[t]{3}{*}{ B cell (luminal B) } & 0.45 & $0.26-0.76$ & $2.90 \times 10^{-3}$ & 0.40 & $0.13-1.25$ & $1.16 \times 10^{-1}$ & 0.84 & $0.31-2.31$ & $7.39 \times 10^{-1}$ \\
\hline & \multicolumn{3}{|c|}{ Rotterdam RFS } & \multicolumn{3}{|c|}{ Stockholm RFS } & \multicolumn{3}{|c|}{ NKI RFS } \\
\hline & HR & $95 \% \mathrm{CI}$ & $P$ value & $\mathrm{HR}$ & $95 \% \mathrm{CI}$ & $P$ value & $\mathrm{HR}$ & $95 \% \mathrm{CI}$ & $P$ value \\
\hline Mixed & 1.82 & $1.22-2.72$ & $3.55 \times 10^{-3}$ & 0.89 & $0.44-1.81$ & $7.49 \times 10^{-1}$ & 0.85 & $0.59-1.24$ & $4.10 \times 10^{-1}$ \\
\hline CSR & 1.21 & $0.84-1.74$ & $3.02 \times 10^{-1}$ & 1.33 & $1.12-1.58$ & $1.12 \times 10^{-3}$ & 1.22 & $1.09-1.36$ & $4.22 \times 10^{-4}$ \\
\hline B cell & 0.59 & $0.45-0.77$ & $1.00 \times 10^{-4}$ & 1.11 & $0.71-1.73$ & $6.61 \times 10^{-1}$ & 1.35 & $0.98-1.86$ & $7.02 \times 10^{-2}$ \\
\hline B cell (luminal B) & 0.65 & $0.41-1.03$ & $6.58 \times 10^{-2}$ & 0.58 & $0.26-1.30$ & $1.84 \times 10^{-1}$ & 1.17 & $0.53-2.61$ & $6.97 \times 10^{-1}$ \\
\hline \multicolumn{10}{|l|}{ Multivariate } \\
\hline & \multicolumn{3}{|c|}{ Uppsala DSS } & \multicolumn{3}{|c|}{ Stockholm DSS } & \multicolumn{3}{|c|}{ NKI OS } \\
\hline & $\mathrm{HR}$ & $95 \% \mathrm{CI}$ & $P$ value & $\mathrm{HR}$ & $95 \% \mathrm{CI}$ & $P$ value & $\mathrm{HR}$ & $95 \% \mathrm{CI}$ & $P$ value \\
\hline PDGF signature & 1.27 & $1.01-1.60$ & $3.68 \times 10^{-2}$ & 1.48 & $1.06-2.06$ & $2.07 \times 10^{-2}$ & 1.43 & $1.19-1.73$ & $2.01 \times 10^{-4}$ \\
\hline CSR & 1.24 & $1.06-1.45$ & $6.32 \times 10^{-3}$ & 1.15 & $0.92-1.45$ & $2.25 \times 10^{-1}$ & 1.30 & $1.12-1.50$ & $6.47 \times 10^{-4}$ \\
\hline PDGF signature & 1.38 & $1.17-1.63$ & $1.26 \times 10^{-4}$ & 1.34 & $1.02-1.77$ & $3.43 \times 10^{-2}$ & 1.32 & $1.14-1.54$ & $2.97 \times 10^{-4}$ \\
\hline CSR & 1.00 & $0.68-1.47$ & $9.87 \times 10^{-1}$ & 1.26 & $1.03-1.53$ & $2.19 \times 10^{-2}$ & 1.16 & $1.03-1.31$ & $2.00 \times 10^{-2}$ \\
\hline \multicolumn{10}{|l|}{ Finak } \\
\hline Good (reference) & 1.00 & & & 1.00 & & & 1.00 & & \\
\hline Mixed & 1.41 & $0.90-2.19$ & $1.34 \times 10^{-1}$ & 1.18 & $0.56-2.50$ & $6.67 \times 10^{-1}$ & 1.15 & $0.72-1.84$ & $5.50 \times 10^{-1}$ \\
\hline Poor & 2.15 & $0.84-5.47$ & $1.08 \times 10^{-1}$ & 2.02 & $0.67-6.12$ & $2.13 \times 10^{-1}$ & 1.77 & $0.79-3.99$ & $1.70 \times 10^{-1}$ \\
\hline B cell & 0.66 & $0.49-0.89$ & $6.38 \times 10^{-3}$ & 1.02 & $0.68-1.55$ & $9.17 \times 10^{-1}$ & 1.09 & $0.73-1.63$ & $6.80 \times 10^{-1}$ \\
\hline
\end{tabular}

HR, hazard ratio; OS, overall survival.

issue, we compared our signature with 1000 random signatures that were derived in a manner similar to our original signature. In these analyses, we found, for example, for the Uppsala data that, on average, 47 signatures were more significant than the original PDGF signature. However, the prognostic significance of these random signatures was, in contrast to the PDGF signature, largely restricted to individual data sets and diminished dramatically when applied to multiple data sets (Supplemental Tables S5 and S6). In each of $10 \times 4$ tests of random signature runs, $<1.2 \%$ of the random signatures were significant $(P<0.01)$ on all four data sets at the same time and more significant than the PDGF signature.

From a perspective of novel treatments, the present findings also provide additional support for continued efforts to explore stromal PDGF receptor targeting as a treatment strategy for breast cancer. More important, however, studies with anti-stromal drugs will require careful selection of patients, as is the case for tumor cell-targeting drugs. We envisage that this study will facilitate such efforts by providing a novel tool for identification of tumors with active stromal PDGFR signaling. 


\section{Acknowledgment}

We thank Kristian Wennmalm for his expert advice.

\section{Supplemental Data}

Supplemental material for this article can be found at http://dx.doi.org/10.1016/j.ajpath.2013.02.018.

\section{References}

1. Goldhirsch A, Wood WC, Coates AS, Gelber RD, Thürlimann B, Senn H-J: Strategies for subtypes-dealing with the diversity of breast cancer: highlights of the St Gallen International Expert Consensus on the Primary Therapy of Early Breast Cancer 2011. Ann Oncol 2011, 22:1736-1747

2. Bergh J: Quo vadis with targeted drugs in the 21 st century? J Clin Oncol 2009, 27:2-5

3. Liu R, Wang X, Chen GY, Dalerba P, Gurney A, Hoey T, Sherlock G, Lewicki J, Shedden K, Clarke MF: The prognostic role of a gene signature from tumorigenic breast-cancer cells. $\mathrm{N}$ Engl J Med 2007, 356:217-226

4. Taube JH, Herschkowitz JI, Komurov K, Zhou AY, Gupta S, Yang J, Hartwell K, Onder TT, Gupta PB, Evans KW, Hollier BG, Ram PT, Lander ES, Rosen JM, Weinberg RA, Mani SA: Core epithelial-tomesenchymal transition interactome gene-expression signature is associated with claudin-low and metaplastic breast cancer subtypes. Proc Natl Acad Sci U S A 2010, 107:15449-15454

5. Herschkowitz JI, Zhao W, Zhang M, Usary J, Murrow G, Edwards D, Knezevic J, Greene SB, Darr D, Troester MA, Hilsenbeck SG, Medina D, Perou CM, Rosen JM: Breast Cancer Special Feature: comparative oncogenomics identifies breast tumors enriched in functional tumor-initiating cells. Proc Natl Acad Sci U S A 2011 109:2778-2783

6. Shats I, Gatza ML, Chang JT, Mori S, Wang J, Rich J, Nevins JR: Using a stem cell-based signature to guide therapeutic selection in cancer. Cancer Res 2011, 71:1772-1780

7. Miller LD, Coffman LG, Chou JW, Black MA, Bergh J, D'Agostino R, Torti SV, Torti FM: An iron regulatory gene signature predicts outcome in breast cancer. Cancer Res 2011, 71:6728-6737

8. Miller LD, Smeds J, George J, Vega VB, Vergara L, Ploner A, Pawitan Y, Hall P, Klaar S, Liu ET, Bergh J: An expression signature for p53 status in human breast cancer predicts mutation status, transcriptional effects, and patient survival. Proc Natl Acad Sci U S A 2005, 102:13550-13555

9. Wirapati P, Sotiriou C, Kunkel S, Farmer P, Pradervand S, HaibeKains B, Desmedt C, Ignatiadis M, Sengstag T, Schütz F, Goldstein DR, Piccart M, Delorenzi M: Meta-analysis of gene expression profiles in breast cancer: toward a unified understanding of breast cancer subtyping and prognosis signatures. Breast Cancer Res 2008, 10:R65

10. McAllister SS, Weinberg RA: Tumor-host interactions: a far-reaching relationship. J Clin Oncol 2010, 28:4022-4028

11. Karnoub AE, Dash AB, Vo AP, Sullivan A, Brooks MW, Bell GW, Richardson AL, Polyak K, Tubo R, Weinberg RA: Mesenchymal stem cells within tumour stroma promote breast cancer metastasis. Nature 2007, 449:557-563

12. Vermeulen L, De Sousa E, Melo F, Van der Heijden M, Cameron K, De Jong JH, Borovski T, Tuynman JB, Todaro M, Merz C, Rodermond H, Sprick MR, Kemper K, Richel DJ, Stassi G, Medema JP: Wnt activity defines colon cancer stem cells and is regulated by the microenvironment. Nat Cell Biol 2010, 12:468-476

13. McMillin DW, Delmore J, Weisberg E, Negri JM, Geer DC, Klippel S, Mitsiades N, Schlossman RL, Munshi NC, Kung AL, Griffin JD, Richardson PG, Anderson KC, Mitsiades CS: Tumor cell- specific bioluminescence platform to identify stroma-induced changes to anticancer drug activity. Nat Med 2010, 16:483-489

14. Olive KP, Jacobetz MA, Davidson CJ, Gopinathan A, McIntyre D, Honess D, et al: Inhibition of Hedgehog signaling enhances delivery of chemotherapy in a mouse model of pancreatic cancer. Science 2009, 324:1457-1461

15. Pietras K, Ostman A, Sjöquist M, Buchdunger E, Reed RK, Heldin $\mathrm{CH}$, Rubin $\mathrm{K}$ : Inhibition of platelet-derived growth factor receptors reduces interstitial hypertension and increases transcapillary transport in tumors. Cancer Res 2001, 61:2929-2934

16. Pietras K, Rubin K, Sjöblom T, Buchdunger E, Sjöquist M, Heldin C$\mathrm{H}$, Ostman A: Inhibition of PDGF receptor signaling in tumor stroma enhances antitumor effect of chemotherapy. Cancer Res 2002, 62 : 5476-5484

17. Shekhar MPV, Santner S, Carolin KA, Tait L: Direct involvement of breast tumor fibroblasts in the modulation of tamoxifen sensitivity. Am J Pathol 2007, 170:1546-1560

18. Ostman A: The tumor microenvironment controls drug sensitivity. Nat Med 2012, 18:1332-1334

19. Sun Y, Campisi J, Higano C, Beer TM, Porter P, Coleman I, True L, Nelson PS: Treatment-induced damage to the tumor microenvironment promotes prostate cancer therapy resistance through WNT16B. Nat Med 2012, 18:1359-1368

20. Straussman R, Morikawa T, Shee K, Barzily-Rokni M, Qian ZR, Du J, Davis A, Mongare MM, Gould J, Frederick DT, Cooper ZA, Chapman PB, Solit DB, Ribas A, Lo RS, Flaherty KT, Ogino S, Wargo JA, Golub TR: Tumour micro-environment elicits innate resistance to RAF inhibitors through HGF secretion. Nature 2012, 487:500-504

21. Wilson TR, Fridlyand J, Yan Y, Penuel E, Burton L, Chan E, Peng J, Lin E, Wang Y, Sosman J, Ribas A, Li J, Moffat J, Sutherlin DP, Koeppen H, Merchant M, Neve R, Settleman J: Widespread potential for growth-factor-driven resistance to anticancer kinase inhibitors. Nature 2012, 487:505-509

22. Goetz JG, Minguet S, Navarro-Lérida I, Lazcano JJ, Samaniego R, Calvo E, Tello M, Osteso-Ibáñez T, Pellinen T, Echarri A, Cerezo A, Klein-Szanto AJP, Garcia R, Keely PJ, Sánchez-Mateos P, Cukierman E, Del Pozo MA: Biomechanical remodeling of the microenvironment by stromal caveolin-1 favors tumor invasion and metastasis. Cell 2011, 146:148-163

23. Witkiewicz AK, Dasgupta A, Nguyen KH, Liu C, Kovatich AJ, Schwartz GF, Pestell RG, Sotgia F, Rui H, Lisanti MP: Stromal caveolin-1 levels predict early DCIS progression to invasive breast cancer. Cancer Biol Ther 2009, 8:1071-1079

24. Witkiewicz AK, Dasgupta A, Sotgia F, Mercier I, Pestell RG, Sabel M, Kleer CG, Brody JR, Lisanti MP: An absence of stromal caveolin-1 expression predicts early tumor recurrence and poor clinical outcome in human breast cancers. Am J Pathol 2009, 174:2023-2034

25. Paulsson J, Sjöblom T, Micke P, Pontén F, Landberg G, Heldin C-H, Bergh J, Brennan DJ, Jirström K, Ostman A: Prognostic significance of stromal platelet-derived growth factor beta-receptor expression in human breast cancer. Am J Pathol 2009, 175:334-341

26. Becker N, Werft W, Toedt G, Lichter P, Benner A: penalizedSVM: a R-package for feature selection SVM classification. Bioinformatics 2009, 25:1711-1712

27. Finak G, Bertos N, Pepin F, Sadekova S, Souleimanova M, Zhao H Chen H, Omeroglu G, Meterissian S, Omeroglu A, Hallett M, Park M: Stromal gene expression predicts clinical outcome in breast cancer. Nat Med 2008, 14:518-527

28. Wennmalm K, Ostman A, Bergh J: Stromal signature identifies basal breast cancers. Nat Med 2009, 15:237-238; author reply 238

29. Chang HY, Sneddon JB, Alizadeh AA, Sood R, West RB, Montgomery K, Chi J-T, Van de Rijn M, Botstein D, Brown PO: Gene expression signature of fibroblast serum response predicts human cancer progression: similarities between tumors and wounds. PLoS Biol 2004, 2:E7

30. Bianchini G, Qi Y, Alvarez RH, Iwamoto T, Coutant C, Ibrahim NK, Valero V, Cristofanilli M, Green MC, Radvanyi L, Hatzis C, 
Hortobagyi GN, Andre F, Gianni L, Symmans WF, Pusztai L: Molecular anatomy of breast cancer stroma and its prognostic value in estrogen receptor-positive and -negative cancers. J Clin Oncol 2010, 28:4316-4323

31. Pawitan Y, Bjöhle J, Amler L, Borg A-L, Egyhazi S, Hall P, Han X, Holmberg L, Huang F, Klaar S, Liu ET, Miller L, Nordgren H, Ploner A, Sandelin K, Shaw PM, Smeds J, Skoog L, Wedrén S, Bergh J: Gene expression profiling spares early breast cancer patients from adjuvant therapy: derived and validated in two population-based cohorts. Breast Cancer Res 2005, 7:R953-R964

32. Van de Vijver MJ, He YD, van't Veer LJ, Dai H, Hart AAM, Voskuil DW, Schreiber GJ, Peterse JL, Roberts C, Marton MJ, Parrish M, Atsma D, Witteveen A, Glas A, Delahaye L, Van der Velde T, Bartelink H, Rodenhuis S, Rutgers ET, Friend SH, Bernards R: A gene-expression signature as a predictor of survival in breast cancer. N Engl J Med 2002, 347:1999-2009

33. Fan C, Oh DS, Wessels L, Weigelt B, Nuyten DSA, Nobel AB, van't Veer LJ, Perou CM: Concordance among gene-expression-based predictors for breast cancer. N Engl J Med 2006, 355:560-569

34. Wang Y, Klijn J, Zhang Y, Sieuwerts A, Look M, Yang F, Talantov D, Timmermans M, Meijervangekder M, Yu J: Geneexpression profiles to predict distant metastasis of lymph-nodenegative primary breast cancer. Lancet 2005, 365:671-679

35. Sorlie T, Tibshirani R, Parker J, Hastie T, Marron JS, Nobel A, Deng S, Johnsen H, Pesich R, Geisler S, Demeter J, Perou CM, Lønning PE, Brown PO, Børresen-Dale A-L, Botstein D: Repeated observation of breast tumor subtypes in independent gene expression data sets. Proc Natl Acad Sci U S A 2003, 100:8418-8423

36. Calza S, Valentini D, Pawitan Y: Normalization of oligonucleotide arrays based on the least-variant set of genes. BMC Bioinformatics 2008, 9:140

37. Benjamini Y, Hochberg Y: Controlling the false discovery rate: a practical and powerful approach to multiple testing. J R Stat Soc 1995, 57:289-300

38. Yang X, Li J, Lee Y, Lussier YA: GO-Module: functional synthesis and improved interpretation of Gene Ontology patterns. Bioinformatics 2011, 27:1444-1446

39. Augsten M, Hägglöf C, Olsson E, Stolz C, Tsagozis P, Levchenko T, Frederick MJ, Borg A, Micke P, Egevad L, Ostman A: CXCL14 is an autocrine growth factor for fibroblasts and acts as a multi-modal stimulator of prostate tumor growth. Proc Natl Acad Sci U S A 2009, 106:3414-3419

40. Chang HY, Nuyten DSA, Sneddon JB, Hastie T, Tibshirani R, Sørlie T, Dai H, He YD, van't Veer LJ, Bartelink H, Van de Rijn M, Brown PO, Van de Vijver MJ: Robustness, scalability, and integration of a woundresponse gene expression signature in predicting breast cancer survival. Proc Natl Acad Sci U S A 2005, 102:3738-3743

41. Cheang MC, Chia SK, Voduc D, Gao D, Leung S, Snider J, Watson M, Davies S, Bernard PS, Parker JS, Perou CM, Ellis MJ, Nielsen TO: Ki67 index, HER2 status, and prognosis of patients with luminal B breast cancer. J Natl Cancer Inst 2009, 101:736-750

42. Venet D, Dumont JE, Detours V: Most random gene expression signatures are significantly associated with breast cancer outcome. PLoS Comput Biol 2011, 7:e1002240

43. Sotiriou C, Wirapati P, Loi S, Harris A, Fox S, Smeds J, Nordgren H, Farmer P, Praz V, Haibe-Kains B, Desmedt C, Larsimont D, Cardoso F, Peterse H, Nuyten D, Buyse M, Van de Vijver MJ, Bergh J, Piccart M, Delorenzi M: Gene expression profiling in breast cancer: understanding the molecular basis of histologic grade to improve prognosis. J Natl Cancer Inst 2006, 98:262-272

44. Andrae J, Gallini R, Betsholtz C: Role of platelet-derived growth factors in physiology and medicine. Genes Dev 2008, 22:1276-1312

45. Ostman A, Heldin C-H: PDGF receptors as targets in tumor treatment. Adv Cancer Res 2007, 97:247-274

46. Forsberg K, Valyi-Nagy I, Heldin CH, Herlyn M, Westermark B: Platelet-derived growth factor (PDGF) in oncogenesis: development of a vascular connective tissue stroma in xenotransplanted human melanoma producing PDGF-BB. Proc Natl Acad Sci U S A 1993, 90 : 393-397

47. Skobe M, Fusenig NE: Tumorigenic conversion of immortal human keratinocytes through stromal cell activation. Proc Natl Acad Sci U S A 1998, 95:1050-1055

48. Abramsson A, Berlin O, Papayan H, Paulin D, Shani M, Betsholtz C: Analysis of mural cell recruitment to tumor vessels. Circulation 2002, 105:112-117

49. Furuhashi M, Sjöblom T, Abramsson A, Ellingsen J, Micke P, Li H, Bergsten-Folestad E, Eriksson U, Heuchel R, Betsholtz C, Heldin C-H, Ostman A: Platelet-derived growth factor production by B16 melanoma cells leads to increased pericyte abundance in tumors and an associated increase in tumor growth rate. Cancer Res 2004, 64:2725-2733

50. Peña C, Céspedes MV, Lindh MB, Kiflemariam S, Mezheyeuski A, Edqvist $\mathrm{PH}$, Hägglöf $\mathrm{C}$, Birgisson $\mathrm{H}$, Bojmar L, Jirström $\mathrm{K}$, Sandström P, Olsson E, Veerla S, Gallardo A, Sjöblom T, Chang AC, Reddel RR, Mangues R, Augsten M, Ostman A: STC1 expression by cancer-associated fibroblasts drives metastasis of colorectal cancer. Cancer Res 2013, 73:1287-1297

51. Hägglöf C, Hammarsten P, Josefsson A, Stattin P, Paulsson J, Bergh A, Ostman A: Stromal PDGFRbeta expression in prostate tumors and non-malignant prostate tissue predicts prostate cancer survival. PLoS One 2010, 5:e10747

52. Paulsson J, Lindh MB, Jarvius $M$, Puputti $M$, Nistér $M$, Nupponen NN, Paulus W, Söderberg O, Dresemann G, Von Deimling A, Joensuu H, Ostman A, Hasselblatt M: Prognostic but not predictive role of platelet-derived growth factor receptors in patients with recurrent glioblastoma. Int J Cancer 2011, 128:1981-1988

53. Jarvius M, Paulsson J, Weibrecht I, Leuchowius K-J, Andersson A-C, Wählby C, Gullberg M, Botling J, Sjöblom T, Markova B, Ostman A, Landegren U, Söderberg O: In situ detection of phosphorylated platelet-derived growth factor receptor beta using a generalized proximity ligation method. Mol Cell Proteomics 2007, 6:1500-1509

54. Koos B, Paulsson J, Jarvius M, Sanchez BC, Wrede B, Mertsch S, Jeibmann A, Kruse A, Peters O, Wolff JEA, Galla H-J, Söderberg O, Paulus W, Ostman A, Hasselblatt M: Platelet-derived growth factor receptor expression and activation in choroid plexus tumors. Am J Pathol 2009, 175:1631-1637

55. Mercier I, Casimiro MC, Wang C, Rosenberg AL, Quong J, Minkeu A, Allen KG, Danilo C, Sotgia F, Bonuccelli G, Jasmin J-F, Xu H, Bosco E, Aronow B, Witkiewicz A, Pestell RG, Knudsen ES, Lisanti MP: Human breast cancer-associated fibroblasts (CAFs) show caveolin-1 downregulation and RB tumor suppressor functional inactivation: implications for the response to hormonal therapy. Cancer Biol Ther 2008, 7:1212-1225

56. Early Breast Cancer Trialists' Collaborative Group (EBCTCG) Peto R, Davies C, Godwin J, Gray R, Pan HC, Clarke M, Cutter D, Darby S, McGole P, Taylor C, Wang YC, Bergh J, Di Leo A, Albain K, Swain S, Piccart M, Pritchard K: Comparisons between different polychemotherapy regimens for early breast cancer: metaanalyses of long-term outcome among 100,000 women in 123 randomised trials. Lancet 2012, 379:432-444

57. Farmer $\mathrm{P}$, Bonnefoi $\mathrm{H}$, Anderle $\mathrm{P}$, Cameron $\mathrm{D}$, Wirapati $\mathrm{P}$, Wirapati P, Becette V, André S, Piccart M, Campone M, Brain E, Macgrogan G, Petit T, Jassem J, Bibeau F, Blot E, Bogaerts J, Aguet M, Bergh J, Iggo R, Delorenzi M: A stroma-related gene signature predicts resistance to neoadjuvant chemotherapy in breast cancer. Nat Med 2009, 15:68-74

58. Baranowska-Kortylewicz J, Abe M, Pietras K, Kortylewicz ZP, Kurizaki T, Nearman J, Paulsson J, Mosley RL, Enke CA, Ostman A: Effect of platelet-derived growth factor receptor-beta inhibition with STI571 on radioimmunotherapy. Cancer Res 2005, 65:7824-7831

59. Falcon BL, Pietras K, Chou J, Chen D, Sennino B, Hanahan D, McDonald DM: Increased vascular delivery and efficacy of chemotherapy after inhibition of platelet-derived growth factor-B. Am J Pathol 2011, 178:2920-2930 